\title{
Faster, higher, more? Past, present and future dynamics of alpine and arctic flora under climate change
}

\author{
Christian Rixen · Sonja Wipf $\cdot$ Esther Frei $\cdot$ \\ Veronika Stöckli
}

Received: 12 September 2014/ Accepted: 17 September 2014/Published online: 1 October 2014

(C) Swiss Botanical Society 2014

Climate warming affects the biotic environment worldwide, and especially in cold regions such as Arctic and alpine biomes. Enhanced plant growth, shrub encroachment and upward migration of species have been observed as a result (Myers-Smith et al. 2011; Stöckli et al. 2011; Pauli et al. 2012). Profound changes in ecosystem functioning and potential losses of high-alpine and Arctic species are expected under climate warming as cold-adapted plants may be outcompeted by taller growing species or lost as their habitats vanish. Due to their endangerment in spatially limited habitats and low abundance, it is important to study the dynamics of plant species in cold environments under climate change.

In the International Tundra Experiment ITEX (e.g., Elmendorf et al. 2012a), a scientific network of research teams carried out experiments at more than 40 sites focusing on the impact of climate change on plant species in Arctic and alpine vegetation. Similar, multi-year plant manipulation experiments allow comparing annual variation in plant performance with respect to phenological response to climate conditions. The ITEX research combines long-term and short-term experimentations with monitoring and aims

C. Rixen $\cdot$ S. Wipf $(\bowtie) \cdot$ E. Frei $\cdot$ V. Stöckli

WSL Institute for Snow and Avalanche Research SLF,

Flüelastrasse 11, 7260 Davos Dorf, Switzerland

e-mail: wipf@slf.ch

Present Address:

E. Frei

Department of Geography, University of British Columbia,

Vancouver Campus, GEOG 127A, Vancouver, Canada

Present Address:

V. Stöckli

Bergwelten 21 AG, Bahnhofstrasse 8a, 7260 Davos Dorf,

Switzerland to understand ecosystem responses and vulnerability to change.

Across all study sites, the ITEX network found the vegetation height and abundance of growth forms to have changed. Results of long-term changes in control plots were largely consistent with predictions based on warming experiments (Elmendorf et al. 2012b). Inter-site comparisons indicated that shrubs (particularly deciduous shrubs) were increasing over time primarily in sites that were warming rapidly over the study period, but this pattern was only apparent in locations where temperatures were already quite high. In contrast, the vegetation in the coldest tundra sites was relatively insensitive to climate warming.

Many other research projects have addressed changes in species distributions and community composition in cold biomes relative to global change. The focus has recently been on vegetation of mountain regions, where upward migration of plant species can lead to changes in taxonomic and functional species composition. For instance, across European summits evidence for so-called thermophilization was found, i.e., more warm-adapted species increased whereas more cold-adapted species declined (Gottfried et al. 2012). In the short period between 2001 and 2008, this upward migration has caused an increase of local species richness in many boreal-temperate mountain regions, but a decrease in Mediterranean mountain regions (Pauli et al. 2012). Looking at longer time scales, i.e., more than a century, the vegetation change has even accelerated in recent decades, most likely in line with accelerated climate warming (Wipf et al. 2013).

To understand changes of Arctic and alpine plants and communities in response to current climatic change, it is helpful to consider the full range of research approaches: experimental manipulations of the tundra environment, studies of long-term vegetation changes, attempts to 
disentangle different environmental factors like temperature and snow cover, studies of evolutionary changes and plasticity of species, and modeling approaches to predict future vegetation. Such changes in alpine and Arctic flora under climate change were the focus of two conferences in September 2013 in Bergün, Switzerland, with the main aim of presenting the state of the art in this research field. The first conference (co-organized with Robert D. Hollister and Kari Klanderud) focussed on recent work of the ITEX network (see above), while the second conference "Faster, Higher, More" aimed at presenting current research in climate-driven changes in species distribution in alpine and Arctic environments. Presentations ranged from changes in species distribution to phenotypic plasticity and genetic adaptation as mechanisms of change, and also included projections of climate change effects into the future. This special issue of Alpine Botany presents a selection of papers from both conferences.

Climatic warming scenarios, and therefore experimental approaches that simulate it, usually focus on a rise in average temperatures. However, a short-term extreme warming may affect plants differently than a longer-term moderate warming. In an experimental approach comparing the effect of different warming treatments on bryophytes in Northern Sweden (Alatalo et al. 2014, this issue), bryophytes and lichens overall were fairly resistant to different warming scenarios. However, acrocarpous mosses showed a shortterm increase in abundance after a 1-year temperature increase of $3.5^{\circ} \mathrm{C}$, which was not apparent after a gradual increase of temperatures over 3 years. These findings indicate that different types of warming scenarios can make a difference in tundra vegetation.

One of the most important consequences of climate change in cold biomes may be the change in snow cover or snow cover duration, on which several papers in this issue focus. Pickering et al. (2014, this issue) studied changes in snowbed vegetation in an area of the world where such habitats are very rare and are probably becoming increasingly so and hence are threatened: in the Australian Alps. Within 6 years, community trait-weighted means for plant height and leaf area had changed in the part of the snowpatches with the longest snow-lie. This change was mostly driven by the increase of a tall tussock grass, Poa costiniana, which was most abundant in areas with earlier snowmelt. Hence, the findings demonstrate that within a fairly short time, common and competitive species may migrate into habitats that were previously dominated by snowbed specialists, which highlights threats and potentially rapid changes of formerly discrete units of alpine plant communities. Similar to the study in Australia, (Carbognani et al. 2014, this issue) found an increase in species richness and abundance over a 6-year period in snowbed communities in the Italian Alps. In this case, this development did not necessarily occur at the cost of snowbed specialists. However, because of higher plant densities, species co-occurence shifted towards higher species segregation, which indicates more competitive plant-plant interactions. The authors conclude that currently, snowbed communities are in a phase of change with competitive interactions becoming more important, which might be critical for weak competitors among the snowbed plants in the future.

When facing ongoing and future climate change, plant species can respond with migration, phenotypic plasticity or evolution. Bienau et al. (2014, this issue) studied trait plasticity of the crowberry, Empetrum hermaphroditum, under a range of different snow and climate conditions. Across two latitudes ranging from Northern Sweden to central Norway, snow cover had highly consistent effects on growth and reproductive traits. Plants from snow-poor sites had a higher number of flowers and fruits, but smaller ramets and lower above-ground biomass than plants from snow-rich habitats. The authors suggest that Empetrum hermaphroditum may have the potential to cope with changing snow conditions due to its large plasticity of traits.

Mountain plant species with wide elevational ranges are expected to be exposed to different selection pressures at low and high elevation. Estimating the extent of genetic population differentiation contributes to our understanding of selective forces shaping phenotypic variation of plants in response to changing climate conditions. A comparison of quantitative trait differentiation with neutral genetic differentiation of Ranunculus bulbosus populations in the Swiss Alps showed evidence for divergent selection across populations (Frei et al. 2014, this issue). The differing levels of trait differentiation at high and low elevation indicated different selective forces across elevations, which suggests that selection regimes might alter under climate change. Also changes in richness, community and trait composition of alpine habitats may respond differently to climate change depending on their elevation. In their resurvey study, Rosbakh et al. (2014, this issue) found that over the past 50 years, richness increased and functional and taxonomic vegetation composition changed most at lowest sites in the subalpine, while the high-alpine sites showed a decrease in richness and few changes in composition. Potentially, permafrost thaw and thus, increasing soil instability at the highest sites may foster this seemingly counter-intuitive result. It illustrates that vegetation changes may vary at the local scale, and that understanding complex interactions between environmental drivers is crucial to understand ecosystem processes in complex alpine terrain. Consequently, it is useful to investigate community composition along environmental gradients to understand possible responses to climate change. Wehn et al. (2014) studied vegetation changes along a gradient from the coast to the inland of Norway, analyzed effects of snow cover duration 
and aspect on plant diversity and predicted future vegetation based on the existing gradients. The authors found that plant diversity was mostly influenced by the coast-inland gradient, and, beyond that, modified by snow cover duration and aspect. The increase in species richness was mostly driven by increases in dwarf shrubs and graminoids. The predictions showed that species richness is likely to increase in the future, and most in areas with medium to long snow cover duration.

The selection of papers in this Special Issue of Alpine Botany highlights the focus of ongoing research approaches and gives directions of future research needs. Discussions at the conferences suggested that our understanding of vegetation changes in cold biomes will benefit greatly from future studies that focus on (1) the relative importance of environmental factors such as climate, land-use, nutrient input, etc., (2) different levels of biodiversity, i.e., species and genetic diversity, functional traits, etc., (3) the rate of adaptive processes in relation to climate and global change, including evolutionary adaptation, migration, or range shift, (4) factors defining the distributional limits of cold-adapted species both at the "leading" (cold) and at the "trailing" (warm) edge. The organizers of the conferences are grateful for the discussions and presentations, and look forward to more research that was stimulated by the conferences.

\section{References}

Alatalo JM, Jägerbrand AK, Molau U (2014) Climate change and climatic events: community-, functional- and species-level responses of bryophytes and lichens to constant, stepwise, and pulse experimental warming in an alpine tundra. Alp Botany 124(2). doi:10.1007/s00035-014-0133-z
Bienau MJ et al. (2014) Snow cover consistently affects growth and reproduction of Empetrum hermaphroditum across latitudinal and local climatic gradients. Alp Botany 124(2). doi:10.1007/ s00035-014-0137-8

Carbognani M, Tomaselli M, Petraglia A (2014) Current vegetation changes in an alpine late snowbed community in the southeastern Alps (N-Italy). Alp Botany 124(2). doi:10.1007/s00035014-0135-x

Elmendorf SC et al (2012a) Global assessment of simulated climate warming on tundra vegetation: heterogeneity over space and time. Ecol Lett 15

Elmendorf SC et al (2012b) Plot-scale evidence of tundra vegetation change and links to recent summer warming. Nat Clim Change 2

Frei ER, Hahn T, Ghazoul J, Pluess AR (2014) Divergent selection in low and high elevation populations of a perennial herb in the Swiss Alps. Alp Botany 124(2). doi:10.1007/s00035-014-0131-1

Gottfried $M$ et al (2012) Continent-wide response of mountain vegetation to climate change. Nat Clim Change 2

Myers-Smith IH et al (2011) Shrub expansion in tundra ecosystems: dynamics, impacts and research priorities. Environ Res Lett 6

Pauli H et al (2012) Recent plant diversity changes on Europe's Mountain Summits. Science 336

Pickering C, Green K, Barros AA, Venn S (2014) A resurvey of latelying snowpatches reveals changes in both species and functional composition across snowmelt zones. Alp Botany 124(2). doi:10. 1007/s00035-014-0140-0

Rosbakh S, Bernhardt-Römermann M, Poschlod P (2014) Elevation matters: contrasting effects of climate change on the vegetation development at different elevations in the Bavarian Alps. Alp Botany 124(2). doi:10.1007/s00035-014-0139-6

Stöckli V, Wipf S, Nilsson C, Rixen C (2011) Using historical plant surveys to track biodiversity on mountain summits. Plant Ecol Divers 4

Wehn S, Lundemo S, Holten JI (2014) Alpine vegetation along multiple environmental gradients and possible consequences of climate change. Alp Botany 124(2). doi:10.1007/s00035-0140136-9

Wipf S, Stöckli V, Herz K, Rixen C (2013) The oldest monitoring site of the Alps revisited: accelerated increase in plant species richness on Piz Linard summit since 1835. Plant Ecol Divers 6 